\title{
USING BUILDING INFORMATION MODELLING (BIM) IN CONSTRUCTION BUDGET: BENEFITS AND BARRIERS
}

\author{
Stanislav Vitasek \\ Czech Technical University in Prague, Czech Republic \\ stanisla.vitasek@fsv.cvut.cz
}

\begin{abstract}
This article shows ways in which BIM data can be used to create construction budgets item by item. It describes conditions which need to be met in order to use the BIM 5D model in its full value - i.e. this article deals primarily with documents used for creation of a BIM model, with their graphic and non-graphic specifications. The article shows a process based on keeping a close correspondence between construction budget items and BIM model elements. To make it clearer, let us state that there exists a classification system, which matches each model element with an identifier, making it possible to link such element to a budget item or several items. In principle, the most important part is matching a construction element with an identifier, which can be "read" by pricing software. That makes the software able to transform construction elements into budget units. The case study shows an analysis of current situation using information models of two administrative buildings (currently under construction) and links these models to construction budgets. The transferred data made up for more than sixty per cent of construction budget, which means that four fifths of total budget could be predicted from automated calculations.
\end{abstract}

Keywords: BIM 5D, construction budget, cost, quantity takeoff.

\section{Introduction}

As opposed to other branches of industry, construction of a building always leads to a unique result (construction, object, building), which needs an appropriate price estimate. In Czech construction practice it is common to base construction budgets on a detailed calculation of work/construction items. These items are priced according to a common document - Classification of Structures and Works (CSW). However, it is very demanding and time consuming for a worker to create a budget based on this document. The costs of construction and future maintenance may be best influenced during the pre-investment phase of construction. Therefore, it is necessary to pay adequate attention to these stages of the construction life cycle. Every company or institution ought to strive for best possible knowledge of costs, so that they can make informed decisions concerning the construction life cycle. However, even with state of art tools, it is nearly impossible to meet the construction budget exactly. Some expenses are evident only when the construction has been finished. Nevertheless, there are still unexploited ways of coming closer to the factual construction budget. Building Information Modelling (BIM) is one of these ways.

BIM is the current phenomenon of information models within the field of construction business. In the Czech Republic, we have witnessed rapid evolution of BIM in all partial fields of construction. This has brought new challenges to Cost Management (CM) - BIM 5D strives to adapt to local customs and needs of construction modelling. It is the next step which BIM took to enhance its tool portfolio to fit practical needs more appropriately. There are three pillars which BIM and CM may share: creation of the construction budget, cost management during construction, and transfer of data for individual elements comprising the construction model (life cycle, characteristics, etc.) for the needs of facility management. This article deals only with the first pillar - creating the construction budget by means of Building Information Modelling with regard to the Czech national specifics.

\section{Literature Overview}

BIM and its benefits for construction practice have been dealt with in academic articles and magazines, but BIM has also been attracting interest of expert practitioners. Papers and magazine articles often focus on general benefits of using BIM as a sturdy model of construction life cycle. As and example of this, Matejka as well as Ma mention that construction and maintenance costs can be substantially supervised and corrected to fit the investor's needs [1;2]. However, the topic of linking a BIM model directly to the construction budget and the whole field of cost management has not been discussed enough. This is, sadly, caused by low engagement of consultants and engineering companies in publishing their best practices concerning cost management. This striking lack of published 
materials surprises us only more, when we take into account the necessity of the realistic construction budget which could easily be met during construction.

Peter Smith, a cost management expert from the Technical University in Sydney states that: "The development of 5D (Cost) capabilities is gaining momentum and the leading edge project cost management firms are starting to realize the competitive advantages by embracing this 'new-age' approach to cost management". He insists that using BIM 5D in actual construction market leads to substantial competitive advantage [3]. With our eye on BIM 5D possibilities, there is nothing to do but agree. Still, Czech construction market and construction companies have a long way to go before they realize this competitive advantage and seize their chance - implant BIM 5D in regular work processes.

BIM 5D issue is rather complex, and its current potential for budget creation is limited, as is its potential for following cash flow during construction. Creating the construction budget on the basis of the BIM model data depends largely on the level of details of both the graphic and non-graphic part of the model. This has been demonstrated by Krzysztof Zima from the Krakow Technical University, who explores the problems of budget created from incomplete data [4]. We also need to mention that even with a detailed model we are not capable of acquiring real data on $100 \%$ of construction works during the construction phase. That comprises the costs of temporary constructions (scaffolding, formwork, safety constructions, etc.), and the costs connected with positioning of construction.

However, the benefits of using BIM 5D in actual construction budget have been explored by Darren Olsen from the University of Auburn, and his research led to an unsurprising result - usage of BIM cuts the amount of time needed for budgeting in fifth when compared to the "traditional method" of manual matching of construction units and CSW items. Such reduction of the necessary time is significant in itself, but it also causes higher level of precision of budget. Olsen's article points to limiting factors of the current BIM models - Olsen states that the most important of such limiting factors is precision of the model itself [5].

Varied level of detail of graphic and non-graphic information proportionately influences the potential of the BIM model, both in cost management, and other levels of construction business. Unfortunately, in the current Czech market, the drafts of competition do not specify the required level of detail of the information model.

A collective team of authors from universities in Reading and Nottingham deals with drafts of competition and their influence on budgeting in BIM in their work: "Cost Estimation in Building Information Model". The authors state that: "The information requirements for the cost estimation can be summarized into 5 aspects: the building products information, the cost item information, the quantity information, the resource information and the price information" [6]. Unfortunately, the authors have not dealt with the topic in such detail as to suggest the possible solutions. Much as the author agrees with the most influential aspects, he also perceives as necessary to find ways of dealing with these obstacles.

This literature overview focuses mainly on articles and publishings from the international scientific databases Scopus and Web of Science. The reasons behind this choice were primarily high professional quality (each article needs to meet reviewing standards), as well as absence of other sources, especially of books dealing with making of construction budgets, cost management, and building information modelling. The research led to several suggestions, which need to be solved before BIM 5D can be employed in construction generally. The most important points are:

- Requirements for creation of the building information model (graphical and non-graphical),

- Legislative support of BIM for the public sector,

- Requirements for professionality and information technology.

\section{BIM requirements connected to construction budget}

Detailed and high quality drafts of competition are the key to creating a successful BIM model and subsequent implementation of BIM in any environment. This can only be assured by specification in contracting documents (mostly by means of contract appendices) between the submitter and supplier of the model. [7] Concerning the construction budget, the main document is the BIM Execution Plan (BEP) and Table of Parameters. These documents define graphic and non-graphic information about individual construction elements. Graphic standards refer to the foreign 
methodology Level of Development (LOD) due to lack of national standards for information modelling. It is also amended by the requirements in national edicts, which specify the content and extent of project documentation.

LOD states the level of detail of the information model for various stages of project documentation, therefore specifying which parts of construction need to be pictured in the model and which are unnecessary. LOD may be specified on a scale between 100 and 500. The Czech construction permit requires documentation with LOD 300 and construction execution documentation needs to be specified in LOD 350. When LOD is raised, so also time is needed to create an information model and also the complexity of the model. Subsequently, the price of such model rises as well. In current construction practice we face the problem of inexperienced designer companies, which are not able to create a model with high LOD of individual constructions [8].

Non-graphic data consist mainly of characteristics of elements (Table 1). Chosen characteristics are grouped together in a document called the Table of Parameters. These data carry particular potential for usage of the information model during preparations, realization, and facility management. However, this potential is not being used in its full extent in information modelling.

Table 1

Example: Table of Parameters - section vertical constructions - walls [11]

\begin{tabular}{|c|c|c|c|c|c|c|c|}
\hline \multirow{2}{*}{$\begin{array}{c}\text { Character- } \\
\text { istics }\end{array}$} & Unit & Format & Description & Example & \multicolumn{3}{|c|}{ LOD } \\
\cline { 6 - 8 } & & 200 & 300 & 350 \\
\hline $\begin{array}{c}\text { Class of } \\
\text { concrete }\end{array}$ & - & TEXT & $\begin{array}{c}\text { Detailed specification of } \\
\text { material }\end{array}$ & $\begin{array}{c}\text { C20/25 } \\
\text { XF1 }\end{array}$ & & $\mathrm{XSP}$ & $\mathrm{DPS}$ \\
\hline $\begin{array}{c}\text { Level of } \\
\text { reinforcing }\end{array}$ & $\mathrm{kg} \cdot \mathrm{m}^{-3}$ & $\mathrm{NUM}$ & $\begin{array}{c}\text { Numeric value describing the } \\
\text { amount of reinforcement per } \\
\mathrm{m}^{3} \text { of concrete }\end{array}$ & 13.9 & $\mathrm{X}$ & $\mathrm{X}$ \\
\hline $\begin{array}{c}\text { Compactness } \\
\text { of walling }\end{array}$ & $\mathrm{Mpa}$ & $\mathrm{NUM}$ & $\begin{array}{c}\text { Compactness of walling under } \\
\text { pressure }\end{array}$ & 2.15 & & & $\mathrm{X}$ \\
\hline $\begin{array}{c}\text { Compactness } \\
\text { of mortar }\end{array}$ & $\mathrm{Mpa}$ & $\mathrm{TEXT}$ & $\begin{array}{c}\text { Compactness of mortar under } \\
\text { pressure }\end{array}$ & $\mathrm{M} 10$ & & & $\mathrm{X}$ \\
\hline Function & - & $\mathrm{TEXT}$ & $\begin{array}{c}\text { Describes whether the element } \\
\text { is inner or outer }\end{array}$ & $\begin{array}{c}\text { Inner; } \\
\text { Outer }\end{array}$ & $\mathrm{X}$ & $\mathrm{X}$ & $\mathrm{X}$ \\
\hline $\begin{array}{c}\text { Static } \\
\text { function }\end{array}$ & - & $\mathrm{TEXT}$ & $\begin{array}{c}\text { Describes whether the element } \\
\text { serves as support for other } \\
\text { structures }\end{array}$ & $\begin{array}{c}\text { Carry; } \\
\text { Non- } \\
\text { carry }\end{array}$ & $\mathrm{X}$ & $\mathrm{X}$ & $\mathrm{X}$ \\
\hline
\end{tabular}

Partial (and/or substandard) use of the information model may be caused by inadequately defined requirements for graphic and non-graphic description of the model. Elements may be faultily drawn and their quantities may not correspond with reality. Or the non-graphic part of the model may not contain data necessary for creation of the construction budget. Documents which ought to define the requirements are, as already stated above, BEP and the Table of Parameters. In practice, we are often faced with the question: "Who is responsible for stating the requirements for BIM?" Is it the competition submitter? Is it the contractor? Is it the investor? Or is it the designer, who actually creates the model? The most meaningful proceeding seems to be when the designer, who knows how to create the model, defines the necessary parameters. The reason behind this statement is the fact that each project has its individual requirements regarding the output data.

\section{Construction budget}

When BIM is used in creating a construction budget, the goal is to reach a higher level of automation, i.e. the easiest possible transfer from the model data to the budgeting item structure. Automation or semi-automation of budget by means of data exported from the model would make the budget not only faster, but also more precise and more efficient. Currently, BIM based programmes allow for export of element materials and amounts. However, exported data concerning the area, 
quantities and numbers of items cannot be fully and meaningfully employed for all types of constructions or construction works yet [12].

To reach the "ideal", i.e. automated transfer of the model data to the itemized budget, at least two requirements need to be met. The first one is adequate choice of the graphic standard with clearly defined LOD or other (ideally national) standard. The second requirement is inclusion of non-graphic descriptors which make automation possible - that is the identification number (identifier) of each element with a clear statement of its function and characteristics. Such identification is guaranteed in construction business by classification systems (CS).

Classification system is of key value for identification of elements and for automated transfer from the information model to the construction budget.

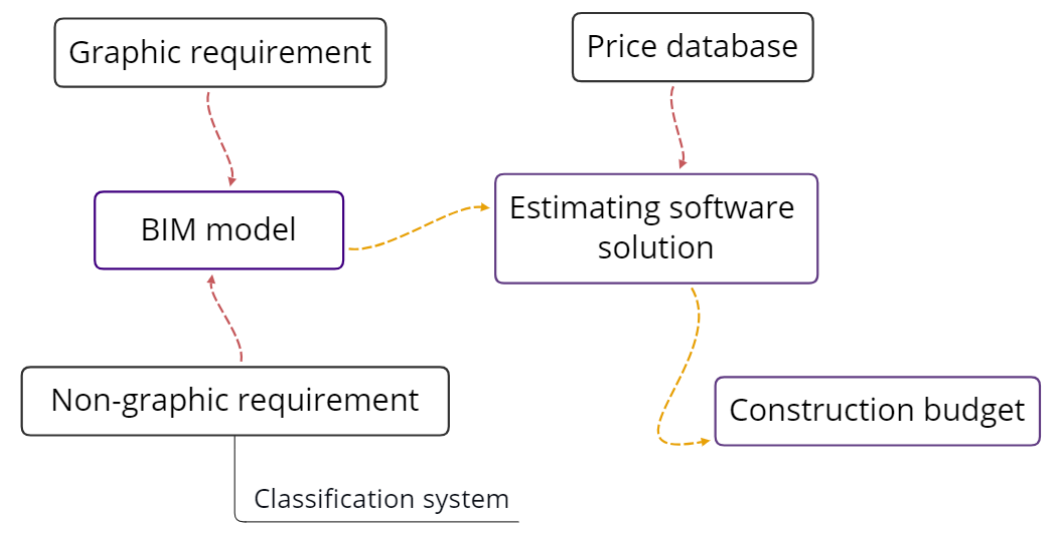

Fig. 1. Scheme of construction budget based on information model data transfer

It is common for every country to have a national classification system, or at least a common structure of elements and work classification. Unfortunately, these traditional classification systems only have a limited scope of use in modern work with data where the element and item are matched 1:1. In the Czech construction market such classification system is represented by the Classification of Structures and Works (CSW). CSW serves as a basis for budgets created by construction companies. It is very demanding to design an information model in such detail that it matches CSW and the corresponding price systems.

Therefore, in many countries, traditional classification systems subside, and are replaced by novel systems, such as Uniclass in Great Britain or CoClass in Sweden. Uniclass and CoClass have already been designed to ease software solutions of construction work. They match corporate software solutions for design (majority of our design companies use Revit, Archicad, etc.) [13]. New classification solutions respect the design software structure and vice versa. Czech market does not currently face a realistic potential for leaving the traditional solution as a whole (because the whole procedure of designing and creating a construction is highly interlinked with CSW). Such intervention in current work processes would cause overloading of all professionals in the construction market and bring more problems than benefits in the current situation. We need to look for a solution, which meets our local needs and also allows us to use full potential of information modelling.

It is essential for the future of BIM 5D to create a classification system (a database of identifiers), which would bridge the gap between the design elements and price system items. Ideally, the items should match the current price system procedures to ease the transition from the traditional to modern model.

Simply said, it is necessary to match each element with an identifier so that it can be "read" and recognized by pricing software. This software would break the elements down into items. Let us state an example: some elements are drawn as a single construction with the "inner structure" (e.g. floors, walls, roofs, etc.). The pricing software analyses the element identifier and matches the element with the "inner structure" to several items of the price system. Similar process may be applied to temporary structures, which are not included in the design ("secondary items" and the scheme of the relationship between items 1:1 and secondary items is shown in Fig. 2) - e.g. a concrete wall may be matched with 
the framework and reinforcement as well as concrete. Quantities of such additional items can be calculated by means of algorithm and matched, e.g. with the quantity of concrete.

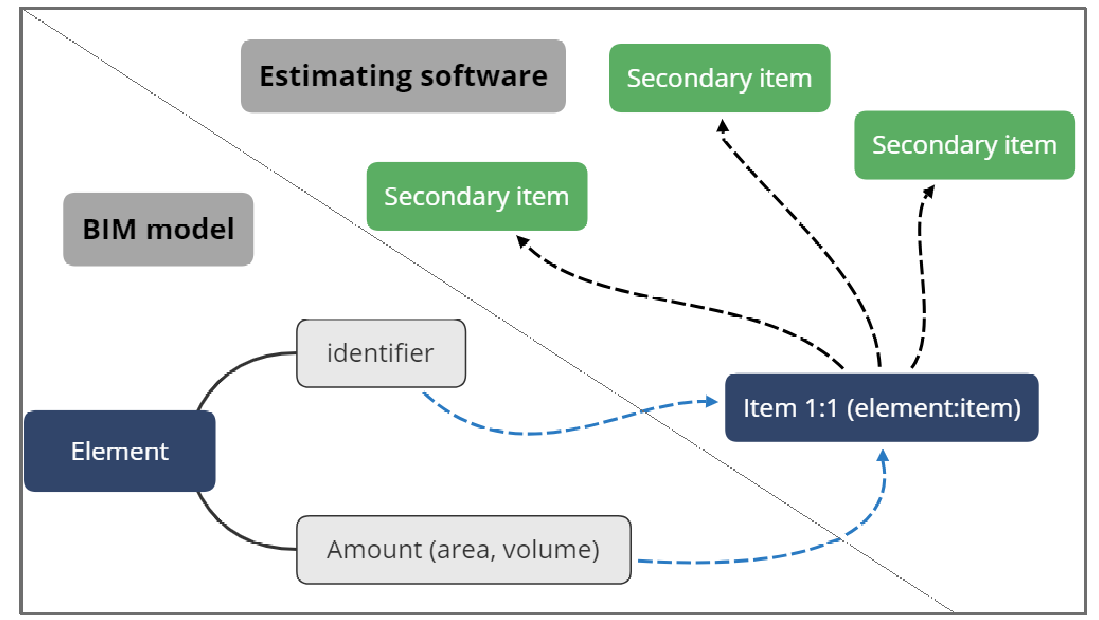

Fig. 2. Scheme of relationship between items 1:1 and secondary items

\section{Analysis of current available models}

The Czech Technical University in Prague obtained two information models of construction of commercial buildings, thanks to the university cooperation with construction companies. It is not always possible to obtain data, as each construction company protects its know-how. These BIM models from 2017 show buildings, which are currently under construction - Parkview and Praga Studios constructions, both in Prague. They are designed with the same carry structure (monolithic framework). Parkview has three more floors, when the two buildings are compared (one garage floor and two above-ground floors).

Case study analyses the way in which data within information models are matched to the construction budget within the local price system. We focused on the amount of data, which can already be directly transferred from the information model to budget on 1:1 level (element: price item). Subsequently, element breakdowns are used, as they are described above and shown in Fig. 2. This shows the amount of "secondary" items and their percentage in the information model. Secondary items are those, which are not depicted in the design (framework, reinforcement, etc.), or which were omitted by the authors of the design, but can be manually matched.

Table 2

Basic information on Parkview and Praga Studios projects [9;10]

\begin{tabular}{|c|c|c|c|c|}
\hline \multirow{4}{*}{ Parkview } & Beginning of construction & $06 / 2018$ & Handover to investor & $03 / 2020$ \\
\cline { 2 - 5 } & $\begin{array}{c}\text { Number of floors (plus } \\
\text { garages) }\end{array}$ & $9(3)$ & Price estimate & $\begin{array}{c}348 \text { million } \\
\text { CZK }\end{array}$ \\
\cline { 2 - 5 } & $\begin{array}{c}\text { Usable floor space (without } \\
\text { garages) }\end{array}$ & $14186 \mathrm{~m}^{2}$ & $\begin{array}{c}\text { Carry construction } \\
\text { system }\end{array}$ & $\begin{array}{c}\text { Monolithic } \\
\text { framework }\end{array}$ \\
\hline \multirow{3}{*}{$\begin{array}{c}\text { Praga } \\
\text { Studios }\end{array}$} & Beginning of construction & $02 / 2017$ & Handover to investor & $10 / 2019$ \\
\cline { 2 - 5 } & $\begin{array}{c}\text { Number of floors (plus } \\
\text { garages) }\end{array}$ & $7(2)$ & Price estimate & $\begin{array}{c}259 \text { million } \\
\text { CZK }\end{array}$ \\
\cline { 2 - 5 } & $\begin{array}{c}\text { Usable floor space (without } \\
\text { garages) }\end{array}$ & $11814 \mathrm{~m}^{2}$ & $\begin{array}{c}\text { Carry construction } \\
\text { system }\end{array}$ & $\begin{array}{c}\text { Monolithic } \\
\text { framework }\end{array}$ \\
\hline
\end{tabular}

Graphic part of the model corresponds with LOD 350. Analysis shows the "quality level" of information modelling within the Czech construction market with respect to quantity takeoff and construction budget.

The results of the analysis are shown in the graphic model in Fig. 5. Both projects show slight dominance of potential for matching elements to items on $1: 1$ basis $(52 \%$ and $54 \%)$. The highest 
potential for such matching was seen in the monolithic framework (84\% and $79 \%$ ), where information models were designed with a careful level of detail.
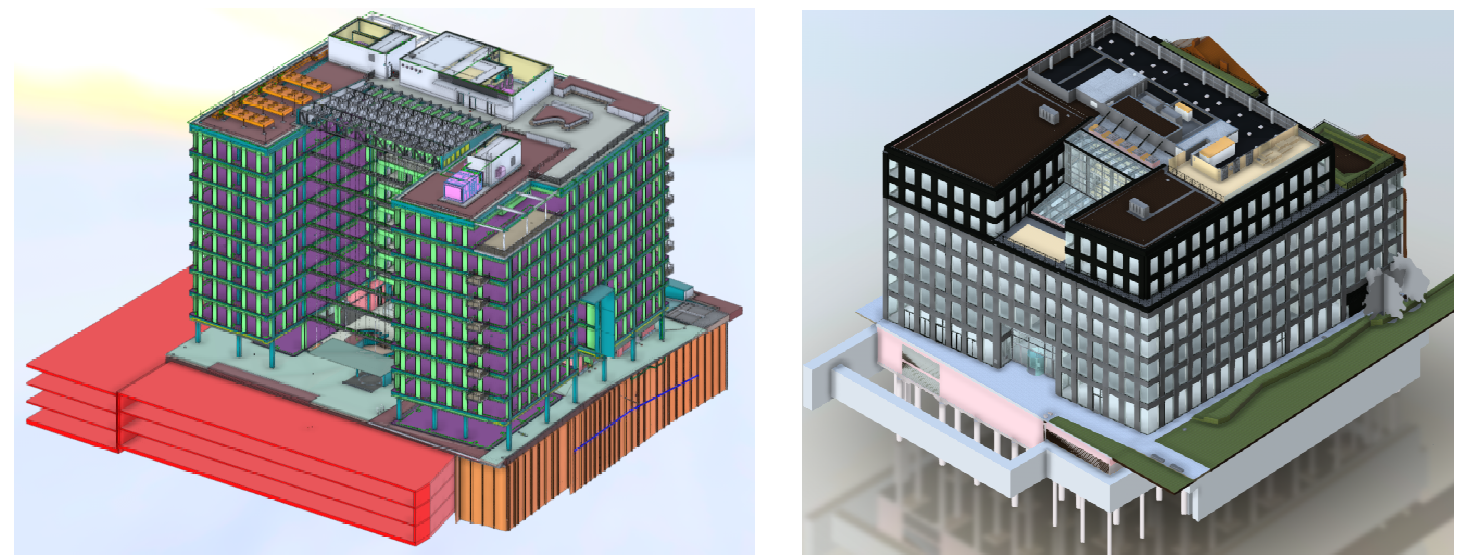

Fig. 3. Information models of Parkview (left) and Praga Studios (right) projects

"Secondary" items required manual corrections of elements before they could be matched to price items. In this category, the best results were seen with plastering. Quantity takeoff exported form the information model did not show plastering directly. But a proper algorithm was used to calculate the wall space with plaster, and the results were strikingly well corresponded with reality. On the other hand, there were constructions, which could not have been calculated by means of the algorithm (e.g. socles for flooring) or were not designed correctly (with adequate level of detail). Typically, these were embankments for groundwork. The authors of the design often connected several layers of embankment with varied levels of aggregate fraction, making the design impossible to read as a breakdown of items.

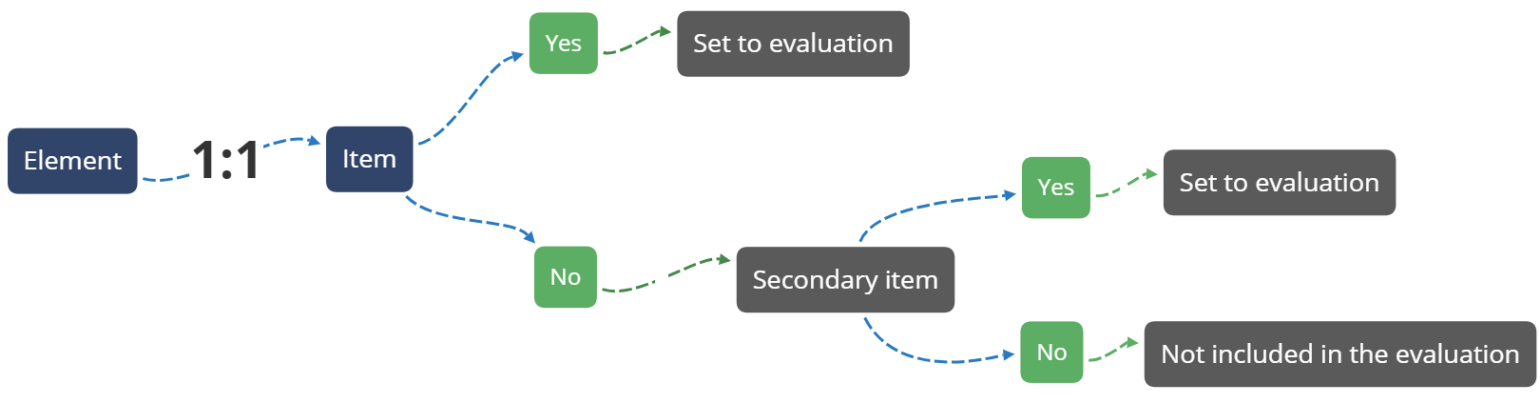

Fig. 4. Scheme of analysis evaluation

In the Parkview project, $63 \%$ of the budget items could be matched either directly or as a secondary item. The total value of matchable elements was 247 million CZK, i.e. roughly $71 \%$ of the total construction budget. Praga Studios brought somewhat better results in this overview - elements matchable either 1:1 or as secondary items show a total score of $69 \%$ of the construction project. That is roughly $78 \%$ of the total construction budget.

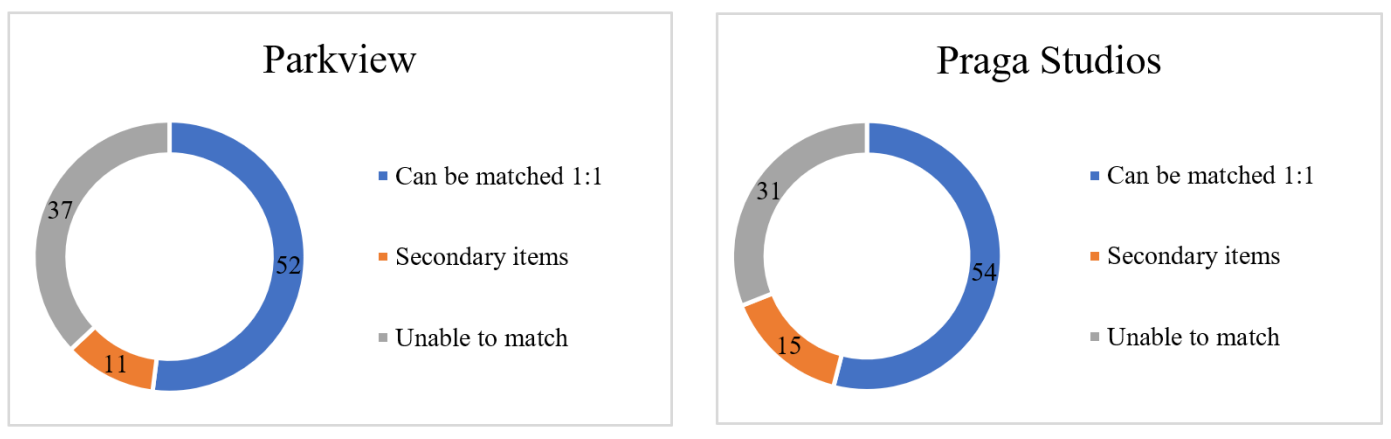

Fig. 5. Assessment of matching construction element: price item 
Both projects, as created by different design companies, show roughly the same quality level. It is also necessary to mention that these information models did not depict fit outs (structures for future clients). It can be successfully assumed that inclusion of fit outs would bring down the percentage of matchable elements. This is caused by varied individual detail and additional construction, which need not be included in the information model.

\section{Conclusions}

1. Like any other innovative method, BIM needs to meet middle European requirements. It needs to bring more benefit than the traditional solution, and this fact needs to be verified by both expert public, as well as investors themselves. It is highly improbable that the BIM model could transfer $100 \%$ of elements to price items (and it is not a realistic goal either). But we might be able to acquire a vast majority of construction elements and works in the itemized structure from the model. This structure may subsequently be linked to the price system, and bring more precision and efficiency to construction preparation.

2. It is necessary to create identifiers within parameters of each construction element. This will enable automated systems to transfer data from the information model to pricing software. Therefore, a database of identifiers is needed (one that takes the current classification system into account) to ensure a possibility of itemized breakdown of elements. This itemized breakdown also needs to be matchable with the current price system. According to the author, this is the easiest way to enable use of BIM in its highest current potential. At the same time, this proceeding shows the least level of threat for current local construction processes.

3. Creation of a pricing software tool enables us to use both visualization of the building information model and to process a breakdown of items (including secondary items) within a chosen price system. The data can then be used for further "traditional" methods of work connected with budget making.

4. The case study has depicted the current state of data obtainable from the information model, which can be - directly or indirectly - transferred to budget. The case study used two current models of buildings, which are under construction during the publishing of this paper. It shows that even with current limited use of information modelling we are capable of matching $66 \%$ of elements to price items. This percentage corresponds with roughly $75 \%$ of the budget of an above ground construction.

\section{Acknowledgements}

This work was supported by the Grant Agency of the Czech Technical University in Prague, grant No. SGS19/017/OHK1/1T/11.

\section{References}

[1] Matejka P., Tomek A. Ontology of BIM in a construction project life cycle. Paper presented at the Procedia Engineering, 196, 2017 pp. 1080-1087.

[2] Ma Z., Liu Z. BIM-based Intelligent Acquisition of Construction Information for Cost Estimation of Building Projects. Paper presented at the Procedia Engineering, 85, 2014, pp. 358-367.

[3] Smith P. Project cost management with 5D BIM. Paper presented at the Procedia Engineering, 226, 2016, pp. 193-200.

[4] Zima K. Impact of information included in the BIM on preparation of Bill of Quantities. Paper presented at the Procedia Engineering, 208, 2017, pp. 203-210.

[5] Olsen D., Taylor M. Quantity Take-Off Using Building Information Modeling (BIM), and Its Limiting Factors. Paper presented at the Procedia Engineering, 196, 2017, pp. 1098-1105.

[6] Xu S., Liu K., Tang L. Cost Estimation in Building Information Model. Paper presented at "International Conference on Construction and Real Estate Management", October 10-11, 2013, Karlsruhe, Germany.

[7] Zak J., Macadam H. Utilization of building information modeling in infrastructure's design and construction. IOP Conference Series: Materials Science and Engineering, Volume 236, 2017. 
[8] Vitasek S., Zak J. Cost estimating and building information modelling (BIM) in road construction. Paper presented at "Creative Construction Conference", 30 June - 3 July, 2018, Ljubljana, Slovenia.

[9] Skanska Czech Republic: Official website for Project Parkview. [online] [29.03.2019]. Available at: https://www.parkviewbyskanska.cz/en.

[10] Skanska Czech Republic: Official website for Project Praga Studios. [online] [29.03.2019]. Available at: https://www.pragastudiosbyskanska.cz//en.

[11]CZBIM: Standardization of non graphic information. [online] [21.4.2019]. Available at: http://www.czbim.org/nodes/nodes/view/type:stranka/slug:standardizace-negrafickych-informaci3d-modelu.

[12] Issa R., Olbina S. Building information modeling: applications and practices. Reston. Virginia: American Society of Civil Engineers, 2015. ISBN 9780784479131.

[13] Vitasek S., Matejka P. Utilization of BIM for automation of quantity takeoffs and cost estimation in transport infrastructure construction projects in the Czech Republic. IOP Conference Series: Materials Science and Engineering, Volume 236, 2017. 